\title{
Synthesis, characterization and photocatalytic activity of titanophosphate glasses
}

\author{
Abdelillah Shaim ${ }^{1}$, Elhassan Amaterz ${ }^{1}$, Yassine Naciri ${ }^{1}$, Aziz Taoufyq ${ }^{1}$, Bahcine Bakiz ${ }^{1}$, \\ Mohamed Ezahri ${ }^{1}$, Abdeljalil Benlhachemi ${ }^{1}$, Abdelkarim Ouammou ${ }^{2}$ and Abdelkrim Chahine ${ }^{3}$ \\ ${ }^{1}$ Laboratoire Matériaux et Environnement (LME), Faculté des Sciences d'Agadir, Maroc \\ ${ }^{2}$ Laboratoire d'Ingénierie des Matériaux Organométalliques et Moléculaires (LIMOM), Faculté des Sciences \\ Dhar El Mahraz, Fès, Maroc \\ ${ }^{3}$ Laboratoire de Physico-Chimie des Matériaux Vitreux et Cristallisés (LPCMVC), Faculté des Sciences Kénitra, \\ Maroc
}

\begin{abstract}
Photocatalytic activity of $(50-\mathrm{x} / 2) \mathrm{Na}_{2} \mathrm{O}-\mathrm{xTiO}_{2}-(50-\mathrm{x} /) \mathrm{P}_{2} \mathrm{O}_{5}$ glasses $(0 \leq \mathrm{x} \leq 10 \mathrm{~mol} \%)$ has been studied with an increase in the $\mathrm{TiO}_{2}$ content using UV-Visible spectrophotometry. Thermal properties were carried out from DTA measurement, and the variation of glass structure was investigated by Fourier Transform Infrared (FT-IR).

The first addition of the $\mathrm{TiO}_{2}$ up to $3 \mathrm{~mol} \%$ entrained depolymerization of the phosphate skeleton $\left(\mathrm{PO}_{3}\right)_{\infty}$ chains in the binary $50 \mathrm{Na}_{2} \mathrm{O}-50 \mathrm{P}_{2} \mathrm{O}_{5}$ glass, resulting in poor cross-linking, which in turn the glass network becomes less rigid and the glass transition temperature $\left(\mathrm{T}_{\mathrm{g}}\right)$ was decreased. Beyond this value, FT-IR reveals the formation of $\mathrm{P}-\mathrm{O}-\mathrm{Ti}$ bonds, which increases the cross-link density in the glass network and therefore increases $\mathrm{T}_{\mathrm{g}}$ of the glasses. The photocatalytic activity results showed that these glasses ensure the discoloration of Rhodamine B by a removal efficiency of about $94 \%$ after $4 \mathrm{~h}$ of irradiation.
\end{abstract}

Keywords: Titanium phosphate glasses, Fourier Transform Infrared Spectroscopy (FTIR), Photocatalysis.

\section{Introduction}

Like silica, phosphorus pentoxide " $\mathrm{P}_{2} \mathrm{O}_{5}$ " is an excellent glass former with a structural entity $\mathrm{PO}_{4}$ tetrahedron, $\mathrm{P}_{2} \mathrm{O}_{5}$ has a much less rigid structure than $\mathrm{SiO}_{2}$ since at maximum, three oxygens are bridging, one less than in silica. This will lead to a significant difference in physicochemical properties such as poor chemical durability which limits their applications ${ }^{1}$.

Phosphate glasses can be described as a regular tetrahedral network based of $\left[\mathrm{PO}_{4}\right]$ groups; their structure is presented using $\mathrm{Q}^{\mathrm{n}}$ terminology, where $\mathrm{n}$ is the number of bridging oxygens per tetrahedron. Depending on the $[\mathrm{O}] /[\mathrm{P}]$ ratio as set by glass composition, the phosphate glasses can be described by different structures: rich $\mathrm{P}_{2} \mathrm{O}_{5}$ network; polymerlike metaphosphate chains of $\mathrm{Q}^{2}$ tetrahedra; 'invert' glasses based on small pyro $\left(\mathrm{Q}^{1}\right)$ and orthophosphate $\left(\mathrm{Q}^{0}\right)$ species.

Phosphate glasses find an ever-increasing and a wide variety of applications in optoelectronic devices, laser host materials, as solid electrolytes, solid state ionic devices, waveguides, bio-implants, optical switches and fibres or power limiters ${ }^{2-5}$, as *Corresponding author: Abdelillah Shaim

Email address: abshaim@hotmail.fr

DOI: http://dx.doi.org/10.13171/mjc8119032221as well as vitrification of radioactive waste ${ }^{6-8}$, photonics ${ }^{9}$, fast ion conductor ${ }^{10}$, and glass-to-metal seals ${ }^{11}$.

These glasses could also be environmentally applicable as they can purify air and water since they can destroy and degrade different organic pollutants ${ }^{12}$.

The additions of $\mathrm{TiO}_{2}$ into oxide glass-forming systems, usually contribute to the stabilization of their structure ${ }^{13-15}$ and the improvement of their properties ${ }^{16,17}$, e.g. chemical durability, mechanical properties, electrical conductivity, etc. However, when $\mathrm{TiO}_{2}$ is added to those glasses, the phosphate chains are depolymerized while Ti-O-P bonds are formed ${ }^{18}$. In this sense, C. Rousselot et al. ${ }^{19}$ have prepared glasses in the system $\left(\mathrm{NaPO}_{3}\right)_{(1-x)}-\left(\mathrm{TiO}_{2}\right)_{\mathrm{x}}$ where the $\mathrm{TiO}_{2}$ content can be up to $40 \%$. FTIR spectroscopy reveals the depolymerization of the phosphate glass network by systematic conversion of metaphosphate chains into pyrophosphate groups and then orthophosphate groups in the richest $\mathrm{TiO}_{2}$ glass. Titanium generally exhibits two valencies in the oxide glasses, namely purple trivalent $\mathrm{Ti}^{3+}$ ion

Received October 16, 2018

Accepted December 17, 2018

Published March 22, 2019 
which occupies the octahedral sites and the colourless tetravalent $\mathrm{Ti}^{4+}$ ion which occupies tetrahedral sites. The probability of the occurrence of $\mathrm{Ti}^{3+}$ or $\mathrm{Ti}^{4+}$ ion depends on the melting process used for the preparation of glass samples ${ }^{20}$. S. Krimi et al. ${ }^{21}$ have synthesized perfectly stable glasses with $\mathrm{TiO}_{2}$ contents of up to $35 \%$. Most of the work cited above worked on glasses with $\mathrm{TiO}_{2}$ contents exceeding 10 mol\%.

Rhodamine B is one of the most important dyes belonging to the xanthene group. Its simple structure is $\mathrm{C}_{28} \mathrm{H}_{31} \mathrm{ClN}_{2} \mathrm{O}_{3}$. It is currently used in the textile industry and the production of laser dyes, which are used for their long wavelengths [22]. It was also, the object of many studies of its photocatalytic degradation in the presence of photocatalysts particles in aqueous media ${ }^{23}$.

The UV-Visible absorption spectrum of an aqueous solution of Rhodamine B shows three bands of absorbance. Two bands are located in the ultraviolet range, and one is visible. In the visible region, the maximum band is located at $554 \mathrm{~nm}$. The other two bands are located at $260 \mathrm{~nm}$ and $356 \mathrm{~nm}$ in the ultraviolet region.

Our interest, in this work, was to obtain using infrared spectroscopy valuable information concerning the structure of the glasses with the general composition $(50-\mathrm{x} / 2) \mathrm{Na}_{2} \mathrm{O}-\mathrm{xTiO}_{2}-(50-$ $\mathrm{x} / 2) \mathrm{P}_{2} \mathrm{O}_{5}$ where the $\mathrm{TiO}_{2}$ content does not exceed 10 mol\%. Furthermore, the influence of this substitution on the evolution of glass transition temperature, density, molar volume and on the photocatalytic degradation of $\mathrm{RhB}$ as a model pollutant is also discussed

\section{Experimental}

\section{Preparation of glasses}

The preparation of the glasses was carried out by direct melting of sodium polyphosphate $\left(\mathrm{NaPO}_{3}-\right.$ extra pure, Riedel- de Haën) and titanium oxide $\left(\mathrm{TiO}_{2}\right.$ - Sigma Aldrich, 99.99\% rutile) reagents mixed in stoichiometric proportions with compositions $(100-\mathrm{x}) \mathrm{NaPO}_{3}-\mathrm{xTiO}_{2} \quad(0 \leq x \leq 10 \% \mathrm{~mol})$. The amount of each product was calculated to obtain $12 \mathrm{~g}$ of phosphate glasses. The weighed materials were thoroughly mixed and pulverized in an agate mortar and then were placed in a porcelain crucible. A first thermal stage at $300^{\circ} \mathrm{C}$ for 2 hours was achieved and then a second stage at $700{ }^{\circ} \mathrm{C}$ for a duration of one hour to minimize the evaporation of $\mathrm{P}_{2} \mathrm{O}_{5}$. The melting temperature of the most refractory composition $\left(1100^{\circ} \mathrm{C}\right)$ is used as the preparation temperature of the entire composition series of this system. Finally, after heating for half an hour at the desired temperature, the glasses were poured into the air on a stainless-steel plate.

\section{Characterizations X-ray diffraction}

The X-ray diffraction patterns were collected on finely ground powder at room temperature using a Siemens D5000 diffractometer with $\mathrm{Cu}_{\mathrm{K}}$ radiation $\left(\lambda_{\mathrm{k} \alpha}=1.5418 \AA\right)$ in the $2 \theta$ ranges from $10^{\circ}$ to $60^{\circ}$ with a scanning speed of $2^{\circ}$ per minute.

\section{Infra-red spectrometry}

The Fourier transformation infrared spectroscopy (FT-IR) was recorded in a Jasco FT / IR 4600 spectrometer equipped with a Jasco ATR PRO ONE module with a resolution of $4 \mathrm{~cm}^{-1}$ and over $400-4000 \mathrm{~cm}^{-1}$ range. For this, the samples glass were crushed to fine powder. A small amount of this powder was mixed and ground with a relatively large quantity of $\mathrm{KBr}(3 \%)$ which is transparent to IR radiation. Discs for IR absorption spectra measurement were formed by pressing it under 10-15 tons of pressure for a few minutes.

\section{Thermal behavior}

The glass transition temperature $T_{g}$ was measured by a differential thermal analyzes (SHIMADZU DTG device) at the range $25-800{ }^{\circ} \mathrm{C}$ with $10{ }^{\circ} \mathrm{C} \mathrm{min}^{-1}$ of heating rate and under a Nitrogen atmosphere. The samples are introduced into alumina crucibles, and the results were corrected by using an empty cell to provide the baseline. The temperatures values are given with about $\pm 5{ }^{\circ} \mathrm{C}$ of estimated accuracy.

\section{Density and molar volume}

The density of the glasses was determined at room temperature using the Archimedes method with diethylorthophtalate as the immersion fluid. The mass glasses used deprived of bubbles.

The following relation made it possible to determine the density values:

$\rho=\frac{M_{\text {air }}}{M_{\text {air }}-M_{\text {imm }}} \rho_{\text {ortho }}$

With:

$\rho_{\text {ortho }}$ : Density of diethylorthophtalate at $\mathrm{T}{ }^{\circ} \mathrm{C}$ $\left(\mathrm{g} / \mathrm{cm}^{3}\right)$,

$\mathrm{M}_{\text {air: }}$ Sample mass in the air $(\mathrm{g})$,

$\mathrm{M}_{\mathrm{imm}}$ : Sample mass immersed in water $(\mathrm{g})$.

The average uncertainty in the measured density was found as $\pm 0.03 \mathrm{~g} / \mathrm{cm}^{3}$. The molar volume $\left(\mathrm{V}_{\mathrm{m}}\right)$ was calculated from the experimentally determined density $(\rho)$ according to the relation:

$V_{m}=\frac{M}{\rho}$

Where $\mathrm{M}$ is the molar weight of the glass.

\section{Photocatalytic experiments}

The photocatalytic activities of the prepared powders were evaluated by the degradation of rhodamine $\mathrm{B}$ in an aqueous medium. Five 
Commercial Puritek lamps (7 W lamp) were used as a UV light source. Each powder (mass of $100 \mathrm{mg}$ ) was suspended in $100 \mathrm{~mL}$ of $\mathrm{RhB}$ solution $(5 \mathrm{mg} / \mathrm{L})$. Before the irradiation, the solution was vigorously stirred for 1 hour in the dark in order to establish the adsorption-desorption equilibrium between the catalyst and $\mathrm{RhB}$. The light was then turned on to initiate the photocatalysis process. About $5 \mathrm{~mL}$ sample was taken each $20 \mathrm{~min}$. The concentration of $\mathrm{RhB}$ was determined as a function of irradiation time using a UV-visible spectrophotometer (UV-2300). The photocatalytic efficiencies were determined from the variation of the concentrations resulting from these intensities:
$\mathrm{I}(\%)=\frac{C_{0}-C}{C_{0}} \times 100$

Where $\mathrm{C}_{0}$ and $\mathrm{C}$ are the concentrations of the solutions before and after UV irradiation, respectively.

\section{Results and discussion}

\section{X-Ray analysis}

Fig. 1 shows the XRD patterns of the five glass samples taken at room temperature. No diffraction peaks on the recorded diffractograms of our synthesized glass samples are observed, but they all show diffuse and broad peaks characteristic of the vitreous state confirming the amorphous structure of our samples.

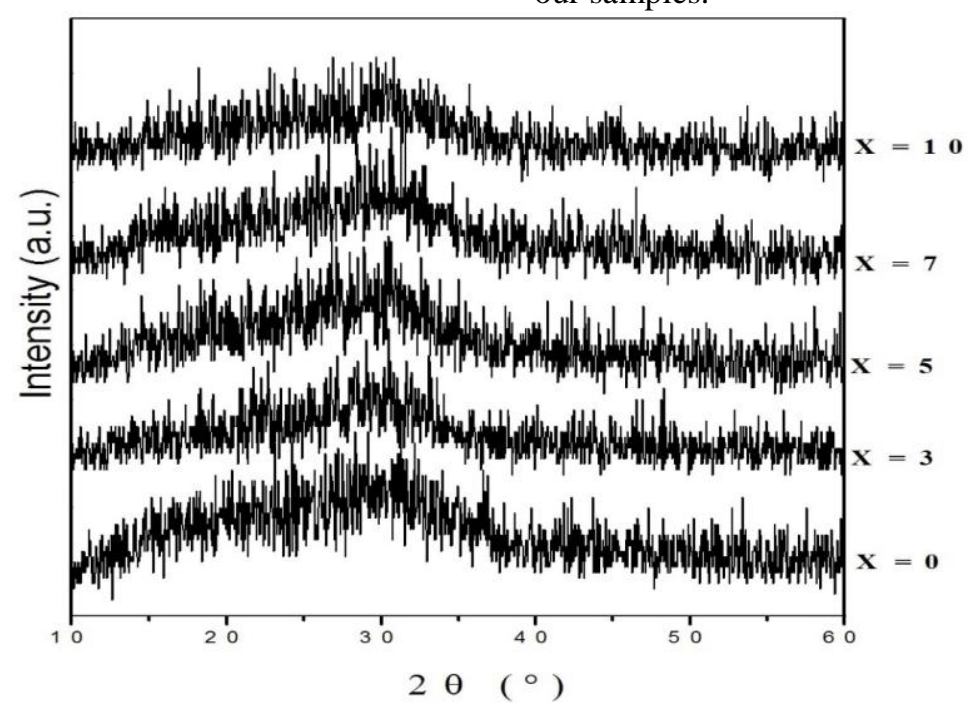

Figure 1. X-ray diffractograms of $\mathrm{xTiO}_{2}-(100-\mathrm{x}) \mathrm{NaPO}_{3}$ glasses $\left(0 \leq \mathrm{x} \leq 10 \mathrm{~mol} \% \mathrm{TiO}_{2}\right)$.

\section{Infra-red spectra}

The infrared spectra of the glass system $(50-\mathrm{x} / 2) \mathrm{Na}_{2} \mathrm{O}-\mathrm{xTiO}_{2}-(50-\mathrm{x} / 2) \mathrm{P}_{2} \mathrm{O}_{5}(0 \leq \mathrm{x} \leq 10 \%$ $\mathrm{mol} \mathrm{TiO}_{2}$ ) in the frequency region $400-1400 \mathrm{~cm}^{-1}$ are represented on Fig.2. The various spectra are composed of fairly wide lines which are typical of amorphous systems.

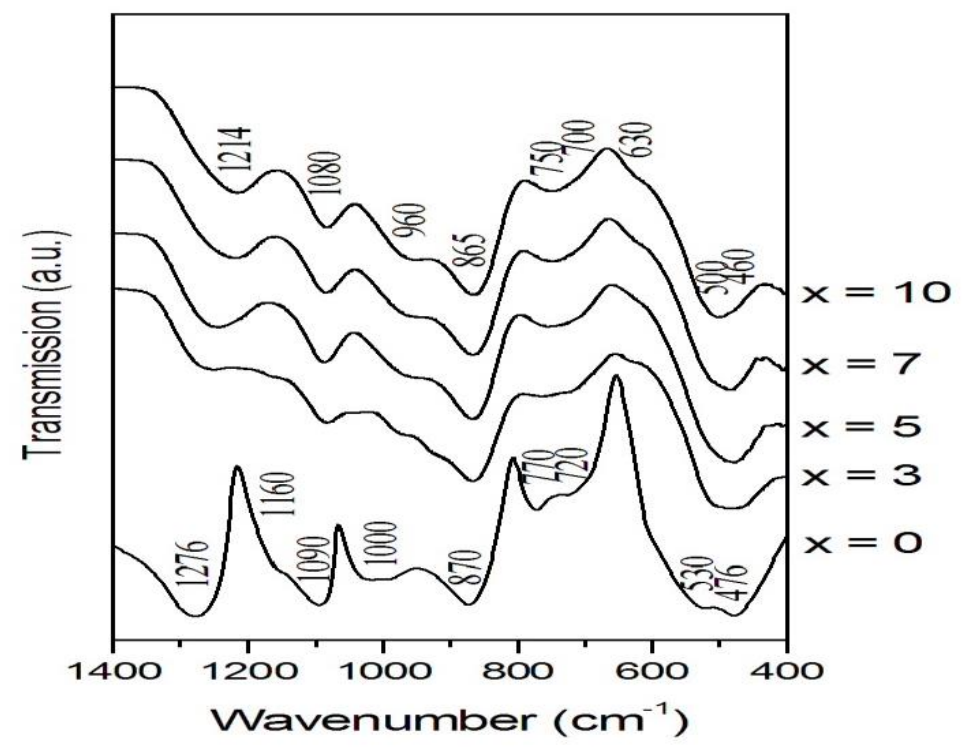

Figure 2. FTIR Spectrum of glasses with composition $(50-\mathrm{x} / 2) \mathrm{Na}_{2} \mathrm{O}-\mathrm{xTiO}_{2}-(50-\mathrm{x} / 2) \mathrm{P}_{2} \mathrm{O}_{5}(0 \leq \mathrm{x} \leq 10 \mathrm{~mol} \%$ 
The representative curve of sodium metaphosphate $50 \mathrm{Na}_{2} \mathrm{O}-50 \mathrm{P}_{2} \mathrm{O}_{5}\left(\mathrm{NaPO}_{3}\right)(\mathrm{x}=0)$ is in agreement with data reported in the literature on this type of composition ${ }^{24}$. The antisymmetric and symmetric valence vibrations of the $\mathrm{PO}_{2}$ groups at 1276 and $1160 \mathrm{~cm}^{-1}$, respectively, are characteristic of highly condensed phosphates ${ }^{20}$. The absorptions at 1090 and $1000 \mathrm{~cm}^{-1}$ correspond respectively to the antisymmetric and symmetric valence vibrations of the $\mathrm{PO}_{3}$ groups (terminal groups). The bands located around $870 \mathrm{~cm}^{-1}$ and around $750 \mathrm{~cm}^{-1}$ (doublet) are attributed respectively to the antisymmetric and symmetric absorptions of the P-O-P bonds. All the deformation vibrations of the $\mathrm{PO}_{4}$ tetrahedra are grouped in the zone $530-470 \mathrm{~cm}^{-125}$.

The spectra corresponding to the glasses containing the titanium ( $\mathrm{x}=3,5,7$ and 10) have absorption bands typical of the metaphosphate glass $\mathrm{NaPO}_{3}$. It is noted that the band attributed to the antisymmetric valence vibration of $\mathrm{PO}_{2} \quad\left(v_{\mathrm{as}} \mathrm{PO}_{2}\right)$ moves from $1276 \mathrm{~cm}^{-1}$ for the $\mathrm{NaPO}_{3}$ glass to 1214 $\mathrm{cm}^{-1}$ for the composition $45 \mathrm{Na}_{2} \mathrm{O}-10 \mathrm{TiO}_{2}-45 \mathrm{P}_{2} \mathrm{O}_{5}$. This result was expected since the phosphate chains interact more strongly with titanium than with sodium and consequently, the phosphorus-oxygen bonds linked to titanium ions $\mathrm{P}-\mathrm{O}(-\mathrm{Ti})$ are longer than those linked to sodium ions $\mathrm{P}-\mathrm{O}(\cdots \mathrm{Na})$. In addition to the displacement of the $v_{\mathrm{as}}\left(\mathrm{PO}_{2}\right)$ bands, it can be observed that the absorption band intensities corresponding to $v_{\text {as }}(\mathrm{O}-\mathrm{P}-\mathrm{O})$ and $v_{\mathrm{s}}(\mathrm{P}-\mathrm{O}-\mathrm{P})$ decrease with increasing $\mathrm{TiO}_{2}$ content. These changes in the spectra of the glasses when the $\mathrm{TiO}_{2}$ content increases are due to a decrease in the length of the phosphate chains ${ }^{26}$. Depolymerization of $\mathrm{NaPO}_{3}$ by titanium oxide $\mathrm{TiO}_{2}$ leads to the formation of short phosphate chains, characterized by the appearance of the $v_{\text {as }}\left(\mathrm{PO}_{2}\right)$ band at $1214 \mathrm{~cm}^{-1}$. This band appears at 1000-1240 $\mathrm{cm}^{-1}$ in tetrapolyphosphates $\left(\mathrm{P}_{4} \mathrm{O}_{13}{ }^{6-}\right)^{27}$ and at $1215 \mathrm{~cm}^{-1}$ in sodium tripolyphosphates $\left(\mathrm{Na}_{5} \mathrm{P}_{3} \mathrm{O}_{10}\right)^{24}$.

For all compositions (exempt and containing titanium), the glasses show two bands around
$770-720 \mathrm{~cm}^{-1}$ which are attributed to the presence of two $\mathrm{P}-\mathrm{O}-\mathrm{P}$ bridges in the metaphosphate-based chains $\left(\mathrm{P}_{2} \mathrm{O}_{6}{ }^{2-}\right)$ (Fig. 3) ${ }^{28}$.

The weak band at $630 \mathrm{~cm}^{-1}$ can be assigned to $\mathrm{Ti}-\mathrm{O}-\mathrm{Ti}$ vibrations since it appears as soon as $\mathrm{TiO}_{2}$ is added to the glasses. This hypothesis is supported by the reported vibrational results for $\mathrm{TiO}_{2}{ }^{29,30}$.

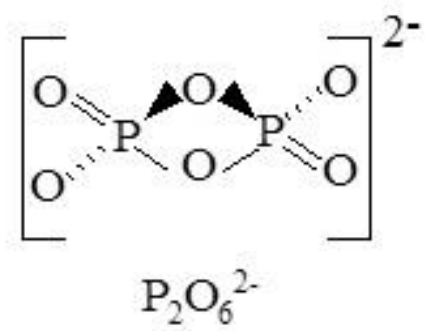

Figure 3. Metaphosphate $\left(\mathrm{P}_{2} \mathrm{O}_{6}\right)^{2-}$ containing two $\mathrm{P}-\mathrm{O}-\mathrm{P}$ units

\section{Density and molar volume}

To better understand the effect of $\mathrm{TiO}_{2}$ content on the properties of the studied glasses, density $(\rho)$ and molar volume $\left(\mathrm{V}_{\mathrm{m}}\right)$ have been studied. Table 1 shows the changes in both density and molar volume during the addition of $\mathrm{TiO}_{2}$ to the system (50$\mathrm{x} / 2) \mathrm{Na}_{2} \mathrm{O}-\mathrm{xTiO}_{2}-(50-\mathrm{x} / 2) \mathrm{P}_{2} \mathrm{O}_{5}$. The density increases with the increase in $\mathrm{TiO}_{2}$ content from 2.51 to 2.63 whereas the molar volume changes in the opposite manner from 40.7 to 38.0. The increase in density may reflect the crosslinking effect of titanium.

As the molar volume is a good structural indicator on the degree of compactness of the vitreous network and the deformation of the oxygen ions, its decrease as a function of the increase in $\mathrm{TiO}_{2}$ confirms that the titanium ions crosslink the vitreous network. The same phenomenon was observed during the study of the glasses of a similar system $(100-\mathrm{x}) \mathrm{NaPO}_{3}-\mathrm{xZnO}{ }^{31}$ and $(100-\mathrm{x}) \mathrm{NaPO}_{3}-$ $\mathrm{xCuO}^{32}$.

Table 1. Density and Molar volume of $(50-\mathrm{x} / 2) \mathrm{Na}_{2} \mathrm{O}-\mathrm{xTiO}_{2}-(50-\mathrm{x} / 2) \mathrm{P}_{2} \mathrm{O}_{5}$ glasses $\left(0 \leq \mathrm{x} \leq 10 \mathrm{~mol} \% \mathrm{TiO}_{2}\right)$

\begin{tabular}{|c|c|c|c|c|c|}
\hline Mol\% $\mathrm{TiO}_{2}$ & 0 & 3 & 5 & 7 & 10 \\
\hline Density $\left( \pm 0.03 \mathrm{~g} / \mathrm{cm}^{3}\right)$ & 2,51 & 2,56 & 2,58 & 2,60 & 2,63 \\
\hline Molar volume $\left(\mathrm{cm}^{3} / \mathrm{mol}\right)$ & 40,7 & 39,6 & 39,1 & 38.7 & 38.0 \\
\hline
\end{tabular}

\section{Glass transition temperature}

The glass transition temperature $\left(\mathrm{T}_{\mathrm{g}}\right)$, which might be a critical thermal property, increased when $\mathrm{TiO}_{2}$ replaced both $\mathrm{Na}_{2} \mathrm{O}$ and $\mathrm{P}_{2} \mathrm{O}_{5}$ as shown in Fig. 4. The increase in the glass transition temperature implies an increase in the rigidity of the network. Indeed, the titanium connects the short chains thus formed using strong P-O-Ti bonds, which replace the weaker P-O-P bonds. This result is in agreement with the evolution of IR spectra. 


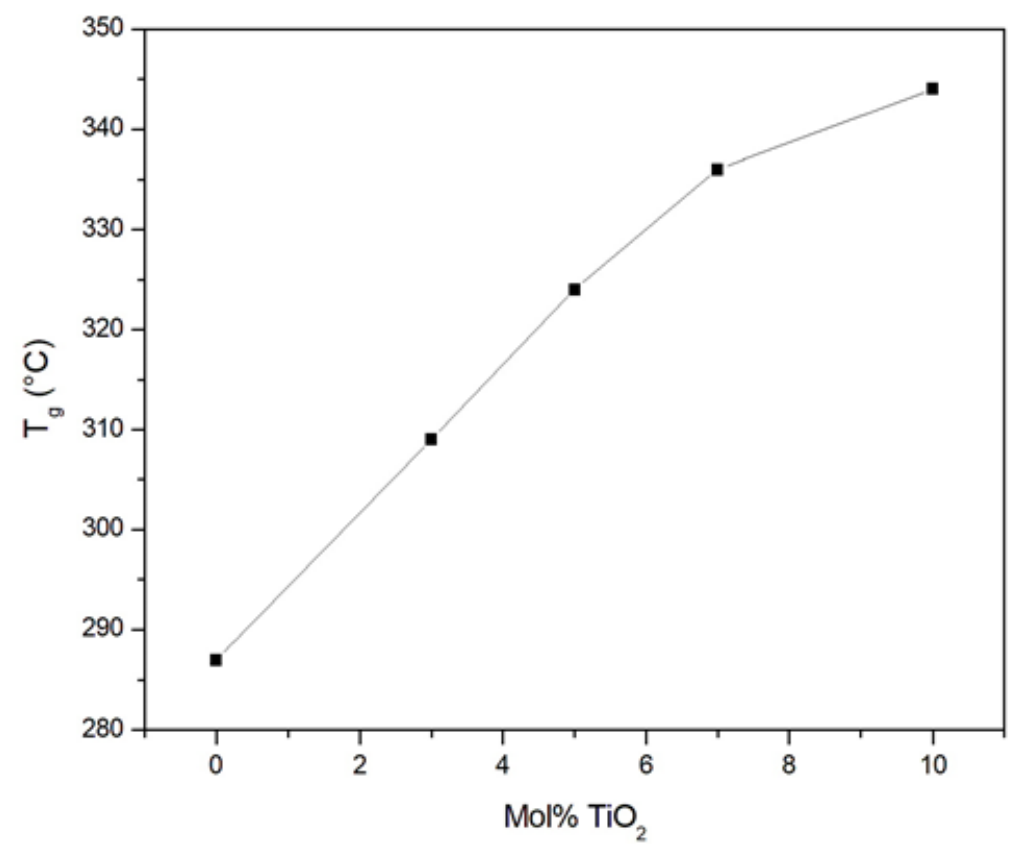

Figure 4. Evolution of the glass transition temperature $\mathrm{T}_{\mathrm{g}}$ as a function of $\mathrm{TiO}_{2}$ content.

\section{Photocatalytic performance}

It is well known that titanium, with gap energy of $3.2 \mathrm{eV}$, presents interesting photocatalytic properties. It has been reported that it can efficiently degrade organic dye molecules under UV illumination. However, in our case, titanium is inserted in an amorphous structure, to identify its photocatalytic properties, a model photocatalytic reaction was carried out by choosing rhodamine $\mathrm{B}$
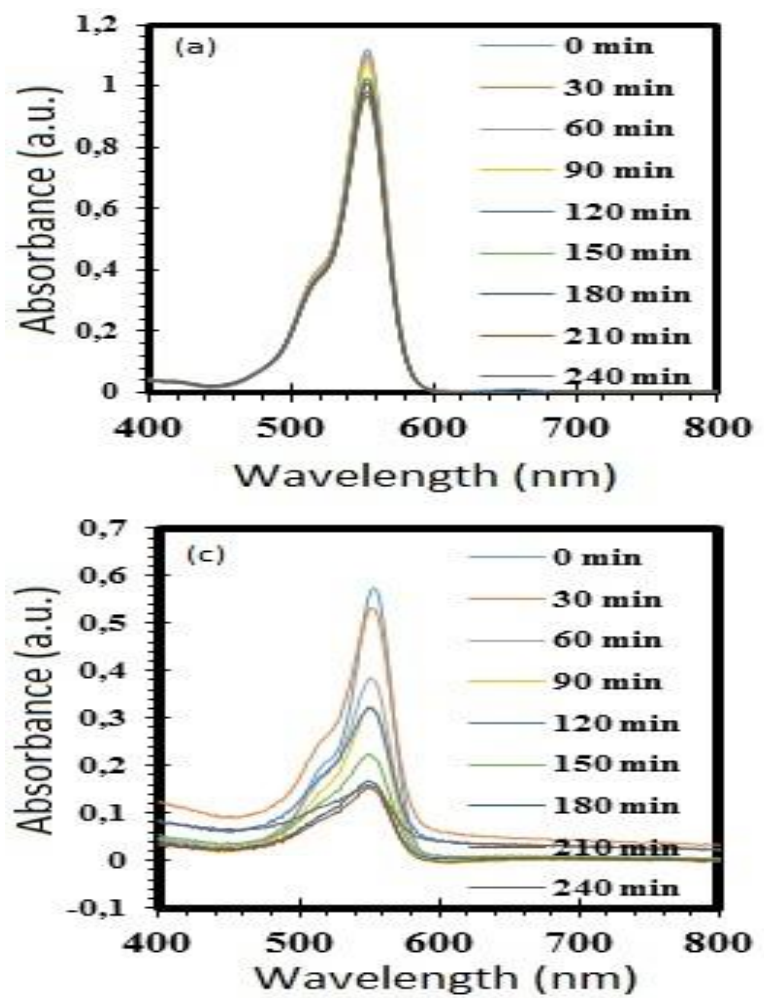

(Rh-B) as a substrate and phosphate glass with different percentages of titanium as a catalyst. The illumination of the catalyst leads to the formation of a positive hole $\left(\mathrm{h}^{+}\right)$in the valence band and an electron $\left(\mathrm{e}^{-}\right)$in the conduction band $(\mathrm{CB})$. This electron before recombination with the hole reacts with the surface-bound water molecule to produce - OH radicals. These radicals then react with the surface-bound organic molecules to degrade them ${ }^{33}$.
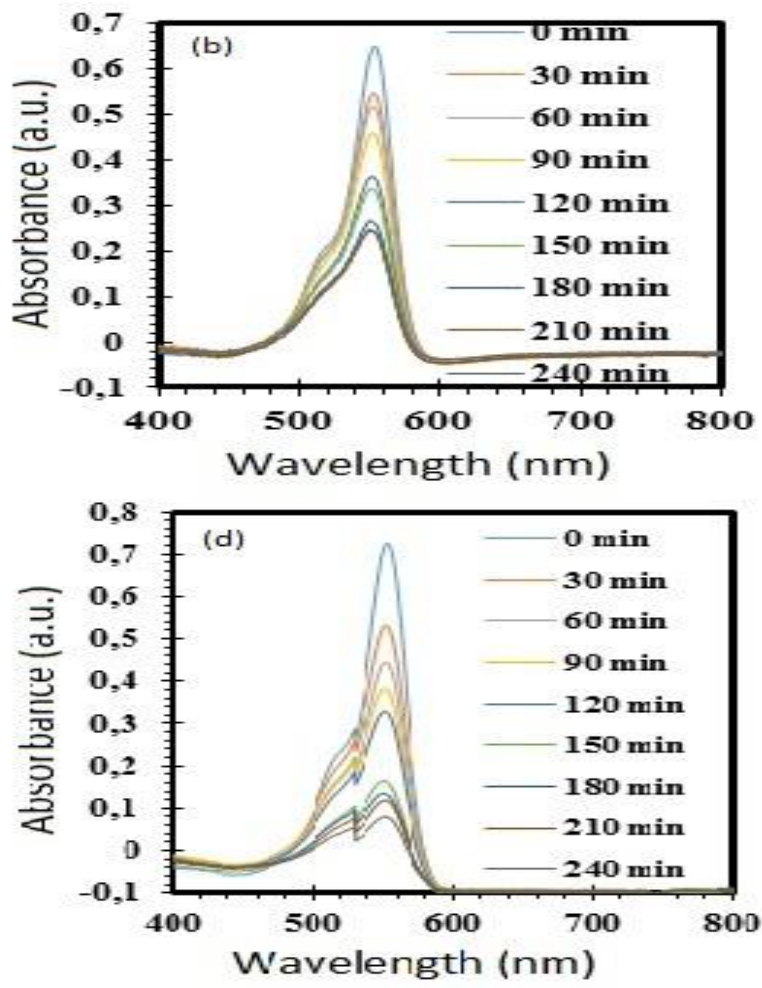

Figure 5. Absorption spectrum of photodegradated RhB under UV excitation: (a) without catalyst, (b) with titanium-free glass, (c) with glass containing $5 \%$ of titanium, and (d) with glass containing $10 \%$ of titanium. 
Figures 5b, 5c and 5d show the evolution of the absorption spectrum of $\mathrm{RhB}$ as well as the changes (decrease) of the adsorption wavelength at $554 \mathrm{~nm}$ for the three phosphate glasses after the UV irradiation. As the figure illustrates, the intensity of the maximum absorption band of $\mathrm{RhB}$ decreases with time in the presence of different catalysts; this decrease varies depending on the titanium percentage. After $4 \mathrm{~h}$ of reaction time, we have almost a complete disappearance of the absorption band at $554 \mathrm{~nm}$ characteristic of the $\mathrm{RhB}$ molecule and consequently its quasi-total transformation, which reaches $94 \%$.
Figure 6 presents the degradation efficiencies of the three samples (glass with 0,5 and $10 \% \mathrm{TiO}_{2}$ ) after 4 hours of irradiation, which are $64 \%, 75 \%$, and $94 \%$, respectively.

Whereas, in the absence of a photocatalyst (Fig. 7), only a $15 \%$ degradation of the $\mathrm{RhB}$ is obtained by the phenomenon of photolysis after 4 hours of irradiation under UV light, which significates that there is not an important degradation of the dye (by photolysis) during the analysis period.

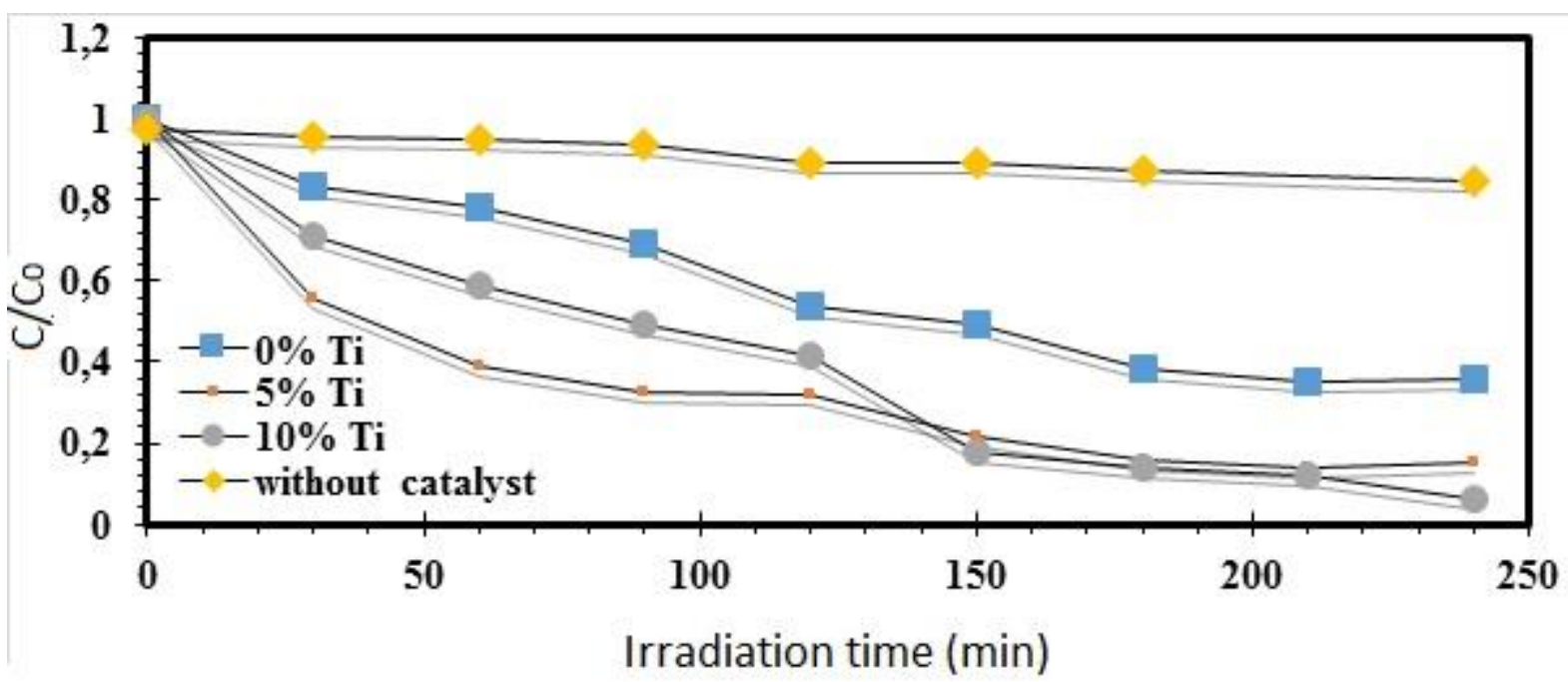

Figure 6. Degradation efficiencies of the as-prepared samples

Figure 6 shows that the degradation follows a pseudo first order kinetics rate law (LangmuirHinshelwood model)

$\operatorname{Ln}\left(\mathrm{C}_{0} / \mathrm{C}\right)=\mathrm{k} . \mathrm{t}$

Where $\mathbf{k}$ is the observed first-order rate constant and $\left[\mathbf{C}_{\mathbf{0}}\right]$ and $[\mathbf{C}]$ are the concentration of $\mathrm{RhB}$ at any time $\mathrm{t}$ and at a time after the adsorption process in dark nature, respectively.

The different values of the reaction constant are given in the following Table 2. As the percentage of titanium increases in the compositions of the glasses, the constant rate increases, which means that titanium enhances the photodegradation process even in its amorphous structure.

Table 2. The $\mathrm{K}$ values of different samples.

\begin{tabular}{|l|c|c|l|c|}
\hline Sample & $10 \% \mathrm{Ti}$ & $0 \% \mathrm{Ti}$ & Without photocatalyst \\
\hline $\mathbf{K}\left(\mathbf{m i n}^{-\mathbf{1}}\right)$ & 0,012 & 0,008 & 0,006 & 0,001 \\
\hline
\end{tabular}

A possible correlation between the photocatalytic activity and sample properties such as glass transition temperature $\left(\mathrm{T}_{\mathrm{g}}\right)$, density $(\rho)$ and molar volume $\left(\mathrm{V}_{\mathrm{m}}\right)$ may exist; as $\mathrm{T}_{\mathrm{g}}$ and $\rho$ increases $\left(\mathrm{V}_{\mathrm{m}}\right.$ decreases), the photocatalytic performance gets higher.

On another side, Ohtani et al. ${ }^{34}$ have reported that photocatalytic activity of amorphous $\mathrm{TiO}_{2}$ is negligible, whereas the photocatalytic activity of anatase, which is having the same particle size as amorphous $\mathrm{TiO}_{2}$, is appreciable.

The value obtained for degradation efficiencies of glass free titanium (64\%) probably due to the adsorption of $\mathrm{Rh}-\mathrm{B}$ on it. Addition of $\mathrm{TiO}_{2}$ increases the degradation efficiency of $47.5 \mathrm{Na}_{2} \mathrm{O}-5 \mathrm{TiO}_{2}$ $47.5 \mathrm{P}_{2} \mathrm{O}_{5}$ and $45 \mathrm{Na} 2 \mathrm{O}-10 \mathrm{Na}_{2} \mathrm{O}-45 \mathrm{P}_{2} \mathrm{O}_{5}$ glasses, indicating that there is a synergistic mechanism for Rh-B degradation by adsorption in $\mathrm{NaPO}_{3}$ and the photocatalytic activity of $\mathrm{TiO}_{2}$. 


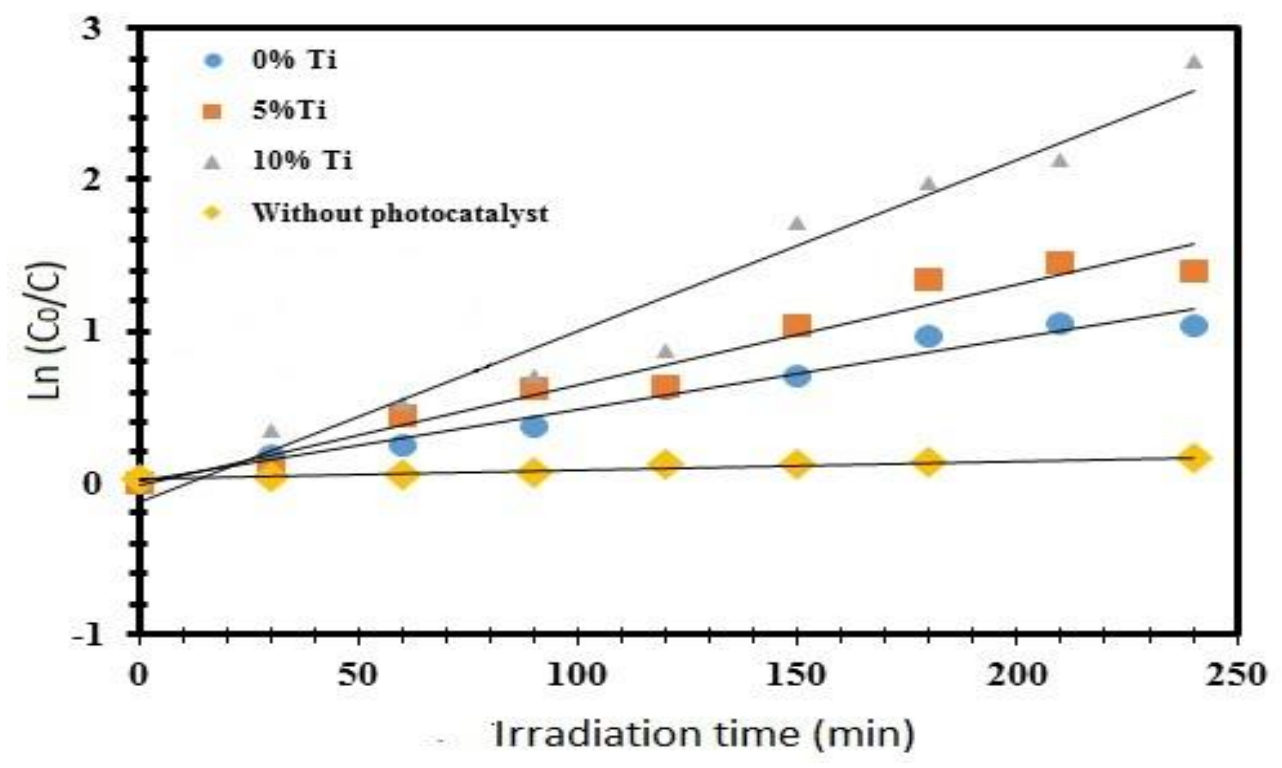

Figure 7. Pseudo-first-order kinetics of the photocatalysts

\section{Conclusion}

In this work, we have synthesized a series of glass compositions in which we have varied the percentage of titanium $(50-\mathrm{x} / 2) \mathrm{Na}_{2} \mathrm{O}-\mathrm{xTiO}_{2}-(50$ $\mathrm{x} / 2) \mathrm{P}_{2} \mathrm{O}_{5}(0 \leq \mathrm{x} \leq 10 \mathrm{~mol} \%)$. The diffractograms of $\mathrm{X}$-ray diffraction have confirmed the amorphous state of. The study of the structure by IR spectroscopy showed that the metaphosphate chains are depolymerized when titanium is added. Once the $\mathrm{TiO}_{2}$ content is sufficient, the structure is crosslinked, and the titanium connects the more formed chains via stronger P-O-Ti bonds than those of P-O$\mathrm{P}$. This description is in complete agreement with the evolution of $\mathrm{T}_{\mathrm{g}}$, the density, and the molar volume.

The results of our study emphasize that the synthesized materials have good photocatalytic activity in the decolorization of an aqueous solution of RhB dye under UV light irradiation. The decolorization extent of dyes was obviously affected by a synergistic mechanism for $\mathrm{Rh}-\mathrm{B}$ degradation by adsorption in $\mathrm{NaPO}_{3}$ and the photocatalytic activity of $\mathrm{TiO}_{2}$. Indeed, their presence leads to a quasi-total disappearance of the organic species studied after a time of irradiation of 4 hours.

\section{Acknowledgements}

This work was carried out in the Laboratory of Materials and Environment (LME), at the Faculty of Sciences, Ibn Zohr University, Agadir, and financially supported by CNRST under number PPR / 2015/32.

\section{References}

1- A. Shaim, M. Et-Tabirou, L. Montagne, G. Palavit, Role of bismuth and titanium in $\mathrm{Na}_{2} \mathrm{O}-\mathrm{Bi}_{2} \mathrm{O}_{3}-\mathrm{TiO}_{2}-\mathrm{P}_{2} \mathrm{O}_{5}$ glasses and a model of structural units. Materials research bulletin, 2002, 37(15), 2459-2466.
2- K. El-Egili, Structure and Physical Properties of $\mathrm{TiO}_{2}-\mathrm{Li}_{2} \mathrm{O}-\mathrm{P}_{2} \mathrm{O}_{5}$ Ion Conducting Glasses. Quantum Matter. 2016, 5(2), 227-232.

3- V. Rajendran, A. G. Devi, M. Azooz \& F. H. El-Batal, Physicochemical studies of phosphate based $\mathrm{P}_{2} \mathrm{O}_{5}-\mathrm{Na}_{2} \mathrm{O}-\mathrm{CaO}-\mathrm{TiO}_{2}$ glasses for biomedical applications. Journal of noncrystalline solids 2007, 353(1), 77-84.

4- E. M. Vogel, S. G. Kosinski, D. M. Krol, J. L. Jackel, S. R. Friberg, M. K. Oliver \& J. D. Powers, Structural and optical study of silicate glasses for nonlinear optical devices. Journal of non-crystalline solids, 1989, 107(2-3), 244-250.

5- G. D. L. K. Jayasinghe, P. W. S. K.

Bandaranayake, M. A. K. L. Dissanayake \& R. $\mathrm{P}$. Gunawardane, Ionic conductivity of glasses in the system $\mathrm{Li}_{2} \mathrm{O}-\mathrm{P}_{2} \mathrm{O}_{5}-\mathrm{TeO}_{2}$. Solid State Ionics, 1995, 78(3-4), 199-202.

6- B. Tiwari, M. Pandey, V. Sudarsan, S. K. Deb \& G. P. Kothiyal, Study of structural modification of sodium aluminophosphate glasses with $\mathrm{TiO}_{2}$ addition through Raman and NMR spectroscopy. Physica B: Condensed Matter, 2009, 404(1), 47-51.

7- T. Okura, T. Miyachi \& H. Monma, Properties and vibrational spectra of magnesium phosphate glasses for nuclear waste immobilization. Journal of the European Ceramic Society, 2006, 26(4), 831-836.

8- P. Bergo, S. T. Reis, W. M. Pontuschka, J. M. Prison \& C. C. Motta, Dielectric properties and structural features of barium-iron phosphate glasses. Journal of non-crystalline solids, 2004, 336(3), 159-164.

9- F. F. Sene, J. R. Martinelli \& L. Gomes, Optical and structural characterization of rare earth doped niobium phosphate glasses. Journal of non-crystalline solids, 2004, 348, 63-71.

10- S. Kumar, P. Vinatier, A. Levasseur \& K. J. Rao, Investigations of structure and transport in 
lithium and silver borophosphate glasses. Journal of Solid State Chemistry, 2004, 177(4), 1723-1737.

11- T. Y. Wei, Y. Hu \& L. G. Hwa, Structure and elastic properties of low-temperature sealing phosphate glasses. Journal of non-crystalline solids, 2001, 288(1), 140-147.

12- J. Fu, Photocatalytic properties of $\mathrm{TiO}_{2}-\mathrm{P}_{2} \mathrm{O}_{5}$ glass ceramics. Materials Research Bulletin, 2011, 46(12), 2523-2526.

13- R. K. Brown, D. R. Tallant, W. L. Warren, A. McIntyre \& D. E. Day, Spectroscopic studies of the structure of titanophosphate and calcium titanophosphate glasses. Physics and chemistry of glasses, 1997, 38(6), 300-306.

14- A. Shaim \& M. Et-Tabirou, Role of titanium in sodium titanophosphate glasses and a model of structural units. Materials chemistry and physics, 2003, 80(1), 63-67.

15- U. Hoppe, R. K. Brow, B. C. Tischendorf, A. Kriltz, P. Jóvári, A. Schöps \& A. C. Hannon, Structure of titanophosphate glasses studied by $\mathrm{X}$-ray and neutron diffraction. Journal of noncrystalline solids, 2007, 353(18), 1802-1807.

16- M. Navarro, M. P. Ginebra, J. Clément, M. Salvador, A. Gloria \& J. A. Planell, Physicochemical Degradation of TitaniaStabilized Soluble Phosphate Glasses for Medical Applications. Journal of the American Ceramic Society, 2003, 86(8), 1345-1352.

17- J. Pospíšil, P. Mošner \& L. Koudelka, Thermal behaviour and crystallization of titanium-zinc borophosphate glasses. Journal of thermal analysis and calorimetry, 2006, 84(2), 479-482.

18- L. Montagne, G. Palavit, A. Shaim, M. EtTabirou, P. Hartmann \& C. Jäger, Structure and ionic conductivity of sodium titanophosphate glasses. Journal of non-crystalline solids, 2001, 293, 719-725.

19- C. Rousselot, E. El Rhess, J.P. Malugani, R. Mercier ', M.F. Mercier, Correlations between structure and conductivity in $\mathrm{NaPO}_{3}$ $\mathrm{TiO}_{2}$ glasses. Solid State Ionics, 1992, 58, 71-76.

20- H. Fatma ElBatal, UV-visible, infrared, Raman and ESR spectra of gamma-irradiated $\mathrm{TiO}_{2}-$ doped soda lime phosphate glasses, Indian J. Pure Appl. Phys., 2009, 47, 631-642

21- S. Krimi, A. El Jazouli, L. Rabardel, M. Couzi, I. Mansouri and G. Le Flem. Glass formation in $\mathrm{Na}_{2} \mathrm{O}-\mathrm{TiO}_{2}-\mathrm{P}_{2} \mathrm{O}_{5}$ system. J. Solid State Chem. 102 (1993) 400-407.

22- A. Chennah, Y. Naciri, A. Taoufyq, B. Bakiz, L. Bazzi, F. Guinneton, S. Villain, J.R. Gavarri, A. Benlhachemi, , Electrodeposited zinc phosphate hydrate electrodes for electrocatalytic applications. J. Appl. Electrochem., 2019, 49 (2) 163-177.

23- A. Chennah, Y. Naciri, H. Ait Ahsaine, A. Taoufyq, B. Bakiz, L. Bazzi, F. Guinneton, J. R. Gavarri \& A. Benlhachemi, Electrocatalytic properties of hydroxyapatite thin films electrodeposited on stainless steel substrates. Mediterranean Journal of Chemistry, 2018, 6(6), 255-266

24- I.V. Tananev, Atlas of infraredspectra of condensed phosphates, IZV. Nouka, Moscow, 1985.

25- R. M. Almeida \& J. D. Mackenzie, Infrared absorption and structure of chlorophosphate glasses. Journal of Non-Crystalline Solids, 1980, 40(1-3), 535-548.

26- D. E. C. Corbridge, \& E. J. Lowe, The infra-red spectra of inorganic phosphorus compounds. Part II. Some salts of phosphorus oxyacids. Journal of the Chemical Society (Resumed), 1954, 4555-4564.

27- A. Rulmont, R. Cahay, M. Liegeoisduyckaerts \& P. Tarte, Vibrational spectroscopy of phosphates-some general correlations between structure and spectra. European Journal of Solid State and Inorganic Chemistry, 1991, 28(1), 207-219.

28- C. Dayanand, G. Bhikshamaiah, V. Jaya Tayagaraju, M. Salagram, A. S. R. Krishna Murthy, J. Mat. Sci., 1996, 31, 1945-1967.

29- C. Xie, , Z. Xu, , Q. Yang, B. Xue, Y. Du \& J. Zhang, Enhanced photocatalytic activity of titania-silica mixed oxide prepared via basic hydrolyzation. Materials Science and Engineering: B, 2004, 112(1), 34-41.

30- Z. Li, B. Hou, Y. Xu, D. Wu \& Sun, Y. Hydrothermal synthesis, characterization, and photocatalytic performance of silicamodified titanium dioxide nanoparticles. Journal of colloid and interface science, 2005, 288(1), 149-154.

31- L. Montagne, G. Palavit \& R. Delaval, Effect of $\mathrm{ZnO}$ on the properties of $(100-\mathrm{x})\left(\mathrm{NaPO}_{3}\right)-\mathrm{xZnO}$ glasses. Journal of non-crystalline solids, 1998, 223(1-2), 43-47.

32- A. Chahine, M. Et-Tabirou, M. Elbenaissi, M. Haddad \& J. L. Pascal, Effect of $\mathrm{CuO}$ on the structure and properties of $(50-\mathrm{x} / 2) \mathrm{Na}_{2} \mathrm{O}-\mathrm{xCuO}-(50-\mathrm{x} / 2) \mathrm{P}_{2} \mathrm{O}_{5}$ glasses. Materials chemistry and physics, 2004, 84(2), 341-347.

33- P. Yuvasree, K. Nithya, N. Neelakandeswari, N. Rajasekaran, K. Uthayarani, M. Chitra \& S. S. Kumar, Phytochemical preparation, Characterization and Photocatalytic applications of $\mathrm{Ag}-\mathrm{TiO}_{2}$ nanocatalyst. In Advanced Materials Research, 2015, 1086, 1-6.

34- N. Xu, Z. Shi, Y. Fan, J. Dong, J. Shi \& M. Z. C. Hu, Effects of Particle Size of $\mathrm{TiO}_{2}$ on Photocatalytic Degradation of Methylene Blue in Aqueous Suspensions. Industrial and Engineering Chemistry Research, 1999, 38, 373. 